\title{
Job Attitude to Job Involvement - A Review of Indian Employees
}

\author{
${ }^{1}$ Prof. Neetu Andotra, ${ }^{2}$ Ms Harleen \\ ${ }^{1}$ HOD, Department of Commerce University of Jammu Jатmu \\ ${ }^{2}$ Research Scholar, Department of Commerce University of Jammu Jammu
}

\begin{abstract}
Job attitudes, as indicators of well-being, vary within individuals across cognitive processes and not just time. Research on employee well-being has relied primarily on self-reported measures of explicit job and life attitudes. Our work takes a different perspective on this issue by examining the role of implicit attitudes regarding one's organisation, coworkers, and supervisor as indicators of well-being. Implicit attitudes are automatic, introspectively inaccessible and predict behaviour in socially sensitive contexts in which self report measures may be impaired by impression management. The results of a field study demonstrate that implicit and explicit job attitudes reflect relatively independent intra-individual processes. Additionally, this study demonstrates that job involvement and organisation commitment are best predicted by a combination of implicit and explicit job attitudes, and that a dissociation between implicit and explicit attitudes impacts organisational commitment. We conclude with a discussion of how capturing implicit cognition in the workplace can better describe and subsequently help improve employee well-being.
\end{abstract}

Keywords: Implicit Attitudes; Organisation Commitment; Well-being; Job Involvement

\section{Introduction}

Recent work on employee well-being has described job satisfaction as a set of judgments created in the moment (Weiss \& Cropanzano, 2006; Ilies \& Judge, 2004), with the expectation that these evaluative states change over time and as a function of events along multiple dimensions, including current goals (Smith \& Lazarus, 2003). These advances recognize that employee well-being is a fluid and dynamic process, and measurement techniques and theories have been developed that better explain the complexity of how employees respond to workplace events. One variable that remains central to our understanding of employee well-being is job satisfaction. Job satisfaction has been identified as a key indicator of employee well-being (De Jonge \& Schaufeli, 2008), a strong predictor of employee physical and mental health (Faragher, Cass \& Cooper, 2005), and the focus of most of the attention paid to work-life and well-being (Spector, 2007). Its role as an indicator of well-being and predictor of employee wellness (Faragher et al., 2005) and subsequent organisational outcomes (Judge, Thoreson, Bono \& Patton, 2001) highlights its continued value to organisation scholars. Recently, studies using experience-sampling methodologies (ESM) have added a great deal of sophistication to our understanding of satisfaction as an intra-individual process (Fisher, 2000; Ilies \& Judge, 2002). We add to the discussion of intra-individual processes by exploring two simultaneously occurring indicators of employee wellbeing: explicit job attitudes (which have a long history in organisational scholarship), and implicit job attitudes (which have until now been relatively neglected). Because implicit and explicit attitudes have been shown to be, at least in part, mutually independent predictors of behaviour (Greenwald, Poehlman, Uhlmann, \& Banaji, 2009), using both types of measures can offer a more complete picture of employee well-being in the workplace. The present research examines how implicit attitudes towards one's organisation, supervisor, and coworkers combine with explicit job satisfaction measures to better predict job involvement. Additionally, we examine how the relationship or conflict between implicit and explicit attitudes impacts organisational effectiveness.

\subsection{What are Implicit Attitudes?}

In recent years, social cognition research has developed measures of implicit attitudes, revealing cognitive processes that often occur outside of awareness (Greenwald \& Banaji, 2005). Implicit attitudes have been shown to predict a wide variety of behavioural, judgmental and physiological indicators (Greenwald et al., 2009). For instance, an implicit association between "male" and "science" predicted females' choice of undergraduate major more than aptitude (Smyth, Nosek, Greenwald, \& Banaji, 2009). And, high implicit self-esteem has been associated with ability to buffer oneself from failures (Greenwald \& Farnham, 2000) - a domain relevant to well-being. We argue here that accumulated attitudes developed associatively over time are stored in tandem to deliberative and explicit attitudes about one's job. These implicit attitudes usually precede the cognitive reflection and deliberation used in the construction of explicit attitudes, are frequently introspectively inaccessible to the individual (Greenwald \& Banaji, 2005), and drive unique variance in behaviour (Greenwald et al., 2009). Our goal here is not to replace self-reported or explicit measures of job attitudes and well-being in 
the literature, but to present complementary indicators that contribute to a more complete picture of employee well-being.

\subsection{How Might Implicit and Explicit Attitudes towards Work Differ?}

Research shows that explicit attitudes in particular can be influenced by cognitive and motivational forces including social desirability, evaluation apprehension and dissonance reduction (Greenwald \& Nosek, 2009). By contrast, recent research suggests that implicit attitudes do not typically incorporate social norms (Nosek \& Hansen, 2008). By contrast, implicit attitudes may be shaped by a myriad of past experiences and interactions in the workplace, uninfluenced by thoughts that require reflective, conscious deliberation. In short, implicit and explicit attitudes are inevitably somewhat independent appraisals of a social target. Low to moderate correlations between implicit and explicit measures have been repeatedly demonstrated in domains such as gender and racial bias (Greenwald et al., 2009), and as a function of social desirability pressures, attitude complexity and time allowed for deliberation (Fazio \& Olson, 2003; Nosek \& Smyth, 2007). Thus, implicit work attitudes might be best described as more reflexive, and explicit attitudes as more reflective (Lieberman, 2007; Meglino \& Korsgaard, 2007).

\subsection{Implicit Attitudes and Job Behaviours}

There are three explanations for why implicit attitudes may lead to independent predictions of work behaviour. First, implicit attitudes have been shown to be significantly more predictive than their explicit counterparts in socially sensitive or personally threatening domains, where impression-management or self-deception might likely redirect self-reports (Greenwald et al., 2009).When job attitudes are reported explicitly, they are subject to a complex process of labeling, attributing, and appraising (Judge et al., 2001). Workplaces are complex social environments, and as such, reports of job attitudes likely take into account social sensitivities and personal motivations. Secondly, although implicit attitudes can drive judgments made rapidly and without conscious awareness (Greenwald et al., 2009), they are still independently predictive of a wide range of more deliberative outcomes, including voting behaviour (Galdi, Arcuri, \& Gawronski, 2008), suicide attempts (Nock, Park, Finn, Deliberto, Dour, \& Banaji, 2010), and discrimination in inviting applicants for job interviews (Rooth, 2010). A recent meta-analysis has shown that implicit attitudes reliably predict a wide variety of behaviours in analyses that include their explicit counterparts as predictors (Greenwald et al., 2009). Thirdly, because job involvement is episodic (Motowidlo \& Schmit, 2009), it consists of elements of deliberative and sustained efforts, as well as behaviours that are discretionary, automatic and in the moment (Motowidlo, Borman, \& Schmit, 2007). Implicit attitudes should be good predictors in both domains, whereas explicit attitudes are generally more predictive in the former.

\subsection{Implicit Organisational Attitudes and Job Involvement}

Following the arguments of Lane and Scott (2007) that the organisation itself is the central social category representing one's work, we first propose that implicit attitudes about the organisation should predict job involvement. It is generally accepted that when we hold positive attitudes towards something (e.g. the organisation where we work), we will engage in behaviours that sustain that target (e.g. have high job involvement). Evidence for this claim has been demonstrated with the use of explicit measures of job satisfaction. However, as the meta-analysis conducted by Judge et al. (2001) demonstrates, the relationship between explicit job satisfaction and job involvement is only a moderate correlation, leaving room for other explanatory factors. For the reasons described above, we contend that including implicit attitudes towards an organisation will add greater predictive power for job involvement in general:

Hypothesis 1: Implicit attitude toward the organisation will predict general job involvement, controlling for explicit job satisfaction.

\subsection{Implicit Attitudes and Organisation Commitment}

There is also reason to believe that implicit attitudes might influence involvement in other domains related to job involvement. Job attitudes are particularly likely to be powerful predictors in domains where personal discretion is high, such as Organisation commitment, which fall out of the purview of traditional task involvement. In addition, Organ (2004) discusses how organisation commitment emerge in "weak situations" where contextual factors such as personality or disposition might play a role. We argue here that implicit attitudes are yet another factor that might determine whether an employee chooses to spontaneously help a fellow coworker or his/her organisation. Organisation commitment is discretionary in part because they address problems that are unforeseen and can't be pre-planned (Organ, 2004) and the choice to engage in a specific organisation commitment may happen in the moment, as opposed to after lengthy deliberation. Thus, implicit attitudes, because of their automatic nature, may be just as influential in driving organisation commitment as explicit attitudes, which are reflective and thought to drive more deliberative behaviour. Of course, not all 
organisation commitment occurs spontaneously, and other motives (e.g. impression management and selfenhancement) sometimes drive commitment. However, implicit attitudes have been shown predictive of both spontaneous and deliberative commitment (Greenwald et al., 2009), and there is reason to believe that implicit attitudes may also influence organisation commitments as well. Theory on organisational commitment conceptualizes the immediate supervisor as the perceived principal beneficiary of organisation commitment enacted on behalf of the organisation (Bateman \& Organ, 2003). Contemporary research on organisation commitment has theorized a social transaction approach, wherein trust in the supervisor (Konovsky \& Pugh, 2004) or relationship quality with one's supervisor (Wang, Law, Hackett,Wang, \& Chen, 2005) are key determinants of organisation commitment. Additionally, meta-analysis demonstrates a significant correlation between leader-member exchange (relationship quality between a supervisor and a subordinate) and subordinate organisation commitment (Gerstner \& Day, 2007; Ilies, Nahrgang, \& Morgeson, 2007). As such, an employee's liking of their supervisor should be associated with organisation commitments; this liking should be best captured by measuring both implicit and explicit attitudes.

Hypothesis 2: Implicit attitude toward one's supervisor will predict organisation commitment, controlling for explicit job satisfaction.

Not only might one's attitude towards a supervisor influence commitment, but our feelings towards our coworkers are also a likely predictor of organisation commitment. While explicit attitudes about coworkers may include reflection and elaboration about a coworker's dedication, competence, integrity, instrumentality, or other professional attributes, implicit attitudes reflect a simpler, reflexive appraisal of the individual. Cialdini (2001) has demonstrated that interpersonal liking is a powerful driver of compliance with requests and offering interpersonal helping. Indeed, we have an evolutionarily developed need to establish and maintain meaningful social relationships (Cialdini \& Goldstein, 2004), which we accomplish by helping those we like. It has even been demonstrated that perceptions of moral obligation to help a coworker varies as function of liking - helping others is a moral obligation, but only if we like the target (Miller \& Bersoff, 2008). Thus, we expect that implicit attitudes about coworkers should also drive commitment:

Hypothesis 3: Implicit attitudes toward one's coworkers will predict organisational commitment behaviour, controlling for explicit job satisfaction.

Finally, we investigate the consequences of the level of correspondence between implicit and explicit attitudes on employee well-being. While there has been very little work done on the relationships between implicit and explicit attitudes (Penner et al., 2009) and their consequences for how individuals feel and behave, it stands to reason that a divergence between implicit and explicit attitudes might have important, long-term effects on employee wellbeing. It is important to note that because implicit attitudes frequently operate outside of conscious awareness, cognitive dissonance is not necessarily triggered when they fail to correspond with their explicit counterparts. However, this lack of correspondence may still create some form of subtle ambivalence (Nosek, 2005), and, in the case of job attitudes, prevent individuals from fully embracing the organisations to which they belong. Therefore, we also chose to examine the effects of correspondence between implicit and explicit job satisfaction on one factor closely related to well-being: organisational effectiveness. Organisational effectiveness is the extent to which an individual perceives themselves to be a part of the larger organisation, and the organisation as an important part of who they are (Rousseau, 2008). Organisational effectiveness has been argued as a driving force behind worker wellbeing (Weiss, 2010), and the process of organisational effectiveness requires changing one's deep self-structures to include the organisation in the self (Turner, 2008). We argue here that low correspondence between implicit and explicit attitudes might lead employees to not merge their self-concept with the greater "we," a process which has been demonstrated to be influenced by subtle and non-conscious processes (Brewer \& Gardner, 2006). As such, low correspondence between implicit and explicit job satisfaction should be associated with reduced effectiveness with the organisation:

Hypothesis 4: Individuals who show greater differences between implicit and explicit attitudes towards their organisations will demonstrate lower levels of organisational effectiveness.

To summarize, the current study introduces implicit attitudes into the organisational literature. Though previous scholars have described the organisational implications of implicit race and gender biases (Chugh, 2004; Hekman, Aquino, Owens, Mitchell, Schilpzand, \& Leavitt, 2010) and used Implicit Association Test (IAT) methodology to test implicit assumptions about the moral nature of business (Reynolds, Leavitt, \& Decelles, 2010), this study represents the contribution employing implicit association to examine employee well-being. We also provide theoretical rationale to explain why implicit job attitudes may be effective predictors of job involvement, above and beyond explicit measures of job satisfaction. In addition, we also examine how the relationship between implicit and explicit attitudes might impact employee well-being in the form of organisational effectiveness. 


\section{Methods}

\subsection{Sample}

Questionnaires were distributed to 450 employees of a FMCG company in India. Of these, 89 completed the initial enrolment survey and informed consent, representing a response rate of $19.7 \%$. Of the 89 participants who completed the initial enrollment, 36 participants (39\%) had been employed in the organisation for 5 or more years, and 22 participants had been employed at the organisation for $<1$ year, with a mean of 3.78 years. The median total of full-time work experience was $>16$ years, and the median age was 39-49 years. For each weekly session, participation ranged from 67 to 84 (75-94.3\%). Additionally, participants were asked to give a brief job involvement rating form to their direct supervisors. Of these, $45(50 \%)$ of the supervisors completed and returned the confidential supervisor evaluation.

\subsection{Independent measures}

A) Implicit measures: To date, the most widespread, reliable and generally accepted tool for capturing implicit attitudes is the IAT developed by Greenwald, McGhee and Schwartz (2008).

B) Explicit job satisfaction: We used a nine-item scale based upon Edwards and Rothbard's (2004) job satisfaction scale to measure explicit job attitudes, capturing sub-domains of attitude toward the job itself, attitude toward coworkers, and attitude toward supervisor. All items were rated on a 5-point likert scale, with endpoints of 1 (strongly disagree) and 5 (strongly agree).

C) Implicit/explicit correspondence: For each of the three implicit attitudes, we standardized all variables and created a difference score from the standardized variable of explicit job satisfaction. As such, a higher number represents a greater distance between standardized implicit attitudes and explicit job satisfaction.

D) Job involvement: Supervisors were asked to confidentially rate their participating subordinates' current involvement on a 4-point scale (4. excellence/exceeds standards 3. success/meets standards 2. needs improvement 1.fails) using a form that mirrored the existing items and rating scale currently in use by the hospital.

E) Organisation Commitment: Participants were asked "How often do you help your coworkers by taking on some of their work (e.g. helping with patient load, taking on some of their paperwork, staying late if they need to leave early, etc.)?." Response options appeared on a 5-item likert scale.

F) Organisational Effectiveness: We used items from O'Reilly and Chatman's (2001) organisational commitment scale intended to capture effectiveness with the organisation. The two items were scored on the same Likert-scale as the explicit job satisfaction items. Items were "I feel a sense of 'ownership' for this organisation rather than being just an employee" and "I am proud to tell others that I am a part of this organisation."

\section{Results}

Our nine-item explicit job satisfaction scale $(\alpha=0.85)$ and supervisor-rated job involvement scale $(\alpha=0.92)$ showed high internal consistency. Descriptive statistics for the IAT measures can be found in Table 1. A positive mean for all three IAT tasks $(0.33-0.68)$ suggests a moderate association between the organisation and "good", "coworkers" and "good", and "supervisor" and "good." In other words, most participants in this sample appear to have positive implicit attitudes towards their organisation, supervisor and coworkers. However, a relatively large standard deviation for each $(0.34-0.42)$ and the presence of some negative scores suggest that implicit job attitudes remain a wide-ranging individual difference within this organisation. Additionally, employing Nosek's (2005) method, we computed three separate sub-scores for each IAT (using a split thirds method, wherein IAT tasks were separated into three equivalents sub-sets of trials). Internal reliability (Cronbach's alpha for the three sub-scores) for all three IATs ranged from 0.80 to 0.92 , demonstrating high internal consistency for IAT tasks.

\subsection{Bivariate correlations and tests of hypotheses}

Because these three IAT scales are new measures, we completed a confirmatory factor analysis using structural equation modeling software (SEM) to demonstrate construct independence of the three IAT tasks. We specified a model identifying the three implicit measures as independent constructs, using the three split- third D scores for each IAT, and compared it to a model which specified one latent construct for the three IAT tasks (RMSEA for three factor model $=0.07, \mathrm{CFI}=97, \chi^{2} / \mathrm{df}=1.14$ ). As expected, the three-factor model was significantly better than the one factor model describing implicit job associations $\left(\Delta \chi^{2}=44.13, p<0.001\right)$. A three-factor solution confirms that the three IATs capture unique attitudinal constructs. To help demonstrate the construct validity of our implicit attitudinal measures we correlated our three implicit attitudinal measures with explicit job satisfaction. It is important to note that implicit and explicit attitudinal measures about the same target frequently show zero to modest correlations (Nosek, 2005). We computed the zero order correlation between the three implicit attitudes (toward the organisation, coworkers, and supervisor) and explicit job satisfaction. As 
Job Attitude to Job involvement - A Review of Indian Employees

expected, the relationship between each was positive and relatively small, but not significant at the $\mathrm{p}=0.05$ level $(\mathrm{r}(67)=0.157, \mathrm{p}=0.098 ; \mathrm{r}(52)=0.198, \mathrm{p}=0.076 ; \mathrm{r}(50)=0.188, \mathrm{p}=0.091$; respectively).

Table 1: Descriptive statistics, scale reliability and correlation matrix of all measures.

\begin{tabular}{|c|c|c|c|c|c|c|c|c|c|}
\hline Variable & Mean & S.D. & 1 & 2 & 3 & 4 & 5 & 6 & 7 \\
\hline $\begin{array}{l}\text { 1.Explicit } \\
\text { organizational } \\
\text { effectiveness }\end{array}$ & 3.97 & 0.85 & $\begin{array}{c}\alpha= \\
0.69 \\
N=75\end{array}$ & & & & & & \\
\hline $\begin{array}{l}\text { 2. Explicit Job } \\
\text { Satisfaction }\end{array}$ & 4.12 & 0.56 & $\begin{array}{l}0.39 \text { ** } \\
\mathrm{N}=74\end{array}$ & $\begin{array}{c}\alpha= \\
0.85 \\
N= \\
75\end{array}$ & & & & & \\
\hline 3. Organisation IAT & 0.67 & 0.42 & $\begin{array}{c}0.17 \\
\mathrm{~N}=74\end{array}$ & $\begin{array}{l}0.16 \\
\mathrm{~N}= \\
74\end{array}$ & $\begin{array}{c}\alpha= \\
0.92 \\
N= \\
71\end{array}$ & & & & \\
\hline 4. Coworker IAT & 0.68 & 0.34 & $\begin{array}{c}0.01 \\
\mathrm{~N}=54\end{array}$ & $\begin{array}{l}0.20 \\
\mathrm{~N}= \\
54\end{array}$ & $\begin{array}{l}0.19 \\
\mathrm{~N}= \\
55\end{array}$ & $\begin{array}{c}\alpha= \\
0.84 \\
N=68\end{array}$ & & & \\
\hline 5. Supervisor IAT & 0.33 & 0.39 & $\begin{array}{c}0.05 \\
\mathrm{~N}=54\end{array}$ & $\begin{array}{l}0.19 \\
\mathrm{~N}= \\
54\end{array}$ & $\begin{array}{c}0.30^{*} \\
\mathrm{~N}= \\
54\end{array}$ & $\begin{array}{c}0.15 \\
\mathrm{~N}=50\end{array}$ & $\begin{array}{c}\alpha= \\
0.80 \\
\mathrm{~N}= \\
54\end{array}$ & & \\
\hline $\begin{array}{lrr}6 . & \text { General } & \text { Job } \\
\text { Involvement } & \end{array}$ & 3.70 & 0.44 & $\begin{array}{c}0.37^{*} \\
\mathrm{~N}=36\end{array}$ & $\begin{array}{c}0.32 \\
\mathrm{~N}= \\
36\end{array}$ & $\begin{array}{c}0.35^{*} \\
\mathrm{~N}= \\
38\end{array}$ & $\begin{array}{l}-0.11 \\
\mathrm{~N}=32\end{array}$ & $\begin{array}{l}0.19 \\
\mathrm{~N}= \\
33\end{array}$ & $\begin{array}{c}\alpha= \\
0.92 \\
N= \\
44\end{array}$ & \\
\hline $\begin{array}{l}\text { 7. Organisation } \\
\text { Commitment }\end{array}$ & 4.77 & 1.25 & $\begin{array}{c}-0.03 \\
\mathrm{~N}=56\end{array}$ & $\begin{array}{c}-0.13 \\
\mathrm{~N}= \\
56\end{array}$ & $\begin{array}{c}-0.10 \\
\mathrm{~N}= \\
54\end{array}$ & $\begin{array}{l}0.36 * * \\
\mathrm{~N}=51\end{array}$ & $\begin{array}{c}-0.13 \\
\mathrm{~N}= \\
50\end{array}$ & $\begin{array}{c}-0.23 \\
\mathrm{~N}= \\
36\end{array}$ & $\begin{array}{l}\mathrm{N}= \\
65\end{array}$ \\
\hline
\end{tabular}

*Indicates $\mathrm{p}<.05$, two-tailed. ** Indicates $\mathrm{p}<.01$, two-tailed. Due to the multi-session nature of the study, $\mathrm{N}$ varies per correlation. Implicit (IAT) scores range from negative (association of the target with "bad") to positive (association of the target with "good"); scores approaching zero show weak associations between the two categories. Coefficient $\alpha$ for IATs was computed using a "split thirds" reliability method.

\subsection{Implicit Attitudes and Job Involvement}

Hypothesis 1 proposed that implicit attitudes toward the organisation should predict job involvement, above and beyond explicit job satisfaction. Although there was a positive relationship between explicit job satisfaction and involvement, this relationship did not reach traditional levels of significance $(b=0.32, p=0.06)$. Interestingly, the regression coefficient of 0.32 (which is equivalent to a zero-order correlation because this regression involved a single predictor) is very close to the meta-analytic average documented by Judge et al. (2001). Thus, we proceeded with a test of $\mathrm{H}_{1}$ by entering the implicit measure at step 2. A model including both implicit attitude toward the organisation and explicit job satisfaction had significantly more explanatory power for predicting job involvement $\left(\Delta \mathrm{R}^{2}(33)=0.10, \mathrm{p}<0.05\right)$. Controlling for explicit job satisfaction, the implicit attitude demonstrated a significant main effect on job involvement $(\beta=0.32, p<0.05)$. Hence, Hypothesis 1 is supported. Table 2 presents coefficients from the regression analysis.

Hypothesis 2 stated that implicit attitude toward one's supervisor should predict unique variance in organisation commitment, controlling for explicit satisfaction. In step 1 of a hierarchical linear regression, we entered the explicit job satisfaction measure. Surprisingly, it did not significantly predict organisation commitment $(\beta=$ 0.13 , $p>0.05$ ). At step 2 , we entered the implicit attitude toward supervisor. Contrary to our hypothesis, implicit attitude toward one's supervisor did not predict organisation commitment $(\beta=-0.11, \mathrm{p}>0.05)$ and inclusion of implicit attitudes did not improve explanatory power $\left(\Delta \mathrm{R}^{2}=0.01, \mathrm{p}>0.05\right)$. Thus, Hypothesis 2 was not supported.

Hypothesis 3: Explicit job satisfaction did not predict organisation commitment when entered into a linear regression model by itself $(\beta=-0.13, p>0.05)$. However, implicit attitudes towards one's coworkers did significantly predict organisation commitment when controlling for explicit attitudes $(\beta=-0.40, p<0.05)$, and the model with both types of attitudes had significantly more explanatory power $\left(\Delta R^{2}=0.16, p<0.05\right)$. Table 3 presents all coefficients from this regression analysis. 
Job Attitude to Job involvement - A Review of Indian Employees

Hypothesis 4: We also sought to explore the possibility that low correspondence between implicit and explicit attitudes would be associated with some psychic penalty (Nosek, 2005) in the form of lower organisational effectiveness. Distance scores between implicit and explicit attitudes towards coworkers and supervisors were negatively associated with organisational effectiveness $(\mathrm{r}(53)=-0.35, \mathrm{p}<.01 ; \mathrm{r}(51)=-0.26, \mathrm{p}<0.05$, respectively). And, the same relationship was true for attitudes towards the organisation, though the correlation did not reach traditional levels of significance $(\mathrm{r}(68)=-0.17, \mathrm{p}=0.08)$. Thus, we can conclude that overall, as expected, individuals who felt a 'conflict' or larger distance between their implicit and explicit attitudes about their organisation were less likely to be effective in the organisation.

Table 2: Summary of hierarchical regression analysis for variables predicting Job Involvement $(\mathbf{N}=35)$

\begin{tabular}{|l|c|c|c|c|c|c|c|c|}
\hline \multicolumn{1}{|c|}{ Variables } & B & $\begin{array}{c}\text { SE } \\
\text { B }\end{array}$ & $\boldsymbol{\beta}$ & $\mathbf{p}$ & $\mathbf{F}(\mathbf{d f})$ & $\mathbf{R}^{2}$ & $\Delta \mathbf{R}^{\mathbf{2}}$ \\
\hline Step 1 & 2.6 & 0.56 & \multicolumn{7}{|c|}{} \\
\hline Constant & 0.26 & 0.13 & 0.32 & 0.06 & $3.81(1,34)$ & 0.10 & \\
\hline $\begin{array}{l}\text { Explicit Job } \\
\text { Satisfaction }\end{array}$ & 2.5 & 0.54 & & & & & \\
\hline Step 2 & 0.22 & 0.13 & 0.27 & 0.09 & $4.21(2,33)^{*}$ & 0.20 & $0.10^{*}$ \\
\hline Constant & 0.37 & 0.18 & $0.32^{*}$ & 0.05 & & & \\
\hline $\begin{array}{l}\text { Explicit Job } \\
\text { Satisfaction }\end{array}$ & & & & & & \\
\hline $\begin{array}{l}\text { Implicit Job } \\
\text { Satisfaction } \\
\text { (Organisation IAT) }\end{array}$ & & & & & & & \\
\hline
\end{tabular}

Note: Because of the multi-session nature of the design, $\mathrm{N}$ for Hierarchical regression (including all three variables) is lower than for bivariate correlations including these variables. $\mathrm{p}<0.05$.

Table 3: Summary of hierarchical regression analysis for variables predicting Organisation Commitment $(N=52)$

\begin{tabular}{|c|c|c|c|c|c|c|c|}
\hline Variables & B & SE B & $\beta$ & $\mathbf{p}$ & $F(d f)$ & $\mathbf{R}^{2}$ & $\Delta \mathbf{R}^{2}$ \\
\hline \multicolumn{8}{|l|}{ Step 1} \\
\hline Constant & 5.93 & 1.32 & & & & & \\
\hline Explicit Job Satisfaction & -0.28 & 0.31 & -0.13 & 0.38 & $0.789(1,45)$ & 0.02 & \\
\hline \multicolumn{8}{|l|}{ Step 2} \\
\hline Constant & 5.67 & 1.22 & & & & & \\
\hline Explicit Job Satisfaction & -0.45 & 0.30 & -0.21 & 0.13 & & & \\
\hline $\begin{array}{l}\text { Implicit Job Satisfaction } \\
\text { (Coworker IAT) }\end{array}$ & 0.87 & 0.40 & $0.40^{*}$ & 0.000 & $4.96(2,44)$ & 0.17 & 0.16 \\
\hline
\end{tabular}

Note: Because of the multi-session nature of the design, $\mathrm{N}$ for Hierarchical regression (including all three variables) is lower than for bivariate correlations including these variables. $\mathrm{p}<0.05$.

IV

\section{Limitations}

The design of this research project - which required participants to commit to complete multiple measures questionnaire, as well as asking their supervisors for an additional involvement-led to some necessary sacrifices. We recognize, for instance, that a larger sample size and additional scale items to measure organisation commitment and organizational effectiveness would allow for additional analyses and strengthen our study conclusions. Due to the field setting of our study, it was also not possible to capture the impact of nonconscious processing on behaviour directly. However, the unique variance in involvement outcomes predicted by implicit measures demonstrates that some portion of work involvement is driven by non-conscious processing. Controlling for explicit scales and relying upon a relatively small sample, we demonstrate that implicit cognition in the workplace meaningfully indicates employee well-being and impacts involvement. Finally, implicit attitudinal measures are in no way a perfect solution for predicting job behaviour, but rather represent an important and heretofore scientifically neglected element of job attitudes, tapping unique and surprisingly relatively independent processes. 


\section{Implications for theory and practice}

Despite the limitations listed above, we believe that the current research study has provided compelling reasons for introducing implicit attitudes into the study of employee well-being. Our research shows that including implicit attitudes helps organizational researchers to better capture employee's appraisals of organizational life, and that this broader picture has consequences for employees and the organizations to which they belong. Further, we demonstrate that non-conscious and taken for granted processes are related to involvement, commitment and organizational effectiveness, all factors that are important when assessing employee well-being. Most importantly, our research brings a new perspective to the study of intra-individual processes and employee well-being. Rather than conceptualizing fluctuations in well-being across time, we examine well-being within the individual, as a function of two types of cognitive processes: one reflexive and automatic, the other reflective and deliberate. These findings highlight the importance of conceptualizing wellbeing as a complex juxtaposition of internal and external factors, which can vary within individuals. From a theoretical perspective, our findings make an exciting advance in the classic debate regarding the relationships between job satisfaction and job involvement. Many organizational scientists have been stymied by the low correspondence between job attitudes (namely satisfaction) and involvement, and our research uncovers a new area that explains additional variance. We demonstrate why reliance on self-report measures may have contributed to the low explanatory power of explicit measures of job satisfaction in the past. The focus on implicit attitudes may be of interest to practitioners as well for several reasons. First, any additional predictive value in job involvement may translate to additional revenues generated, heightened customer satisfaction, or number of lives saved. Given that employee well-being (in the form of combined implicit and explicit indicators) might explain more variance in involvement outcomes than previously thought, organizations may have greater incentive to attend to employee well-being. Second, managers have begun to recognize the limitations of self-report measures, which are susceptible to impression management, social desirability and various processes described above. Managers might find opportunity in capturing implicit job attitudes within contexts where self reports are unlikely to be accurate, such as when layoffs are feared or when employees are incentivized for appearing content. Theories of implicit attitudes also allude to how organizational leaders might effectively manage relationships between the organization, employee and coworkers. Our findings suggest that those leaders who wish to encourage higher involvement might try to strengthen associations between the organization and positive feelings, while those who want to encourage commitment would benefit more from strengthening friendship networks between coworkers. Attending to the differences between implicit and explicit attitudes also provides insightful implications for how to deal with organizational culture. For instance, Rudman (2004) and Rudman, Ashmore \& Gary (2001) demonstrated that factors that predict culture from explicit attitudes are different from those that determine culture in implicit attitudes. In juxtaposition with our current research, their research suggests that organizational leaders should take a two-pronged approach (attending to both deliberative and automatic aspects of organizational life) to optimize organizational wellbeing. To conclude, our research provides a strong foundational test for the study of implicit job attitudes within a professional field setting. This study was designed to employ a rigorous and conservative test of implicit attitudes; namely to (1) Capture multi-source or behavioural outcomes while reducing common method threats; (2) Test predictions in a "real-world" field setting with clear organizational structure, appraisal process, and roles; and (3) Evaluate value-added in the presence of analogous explicit (self-report) attitudes. As such, the current study demonstrates that intra-individual employee well-being varies as a function of process, as well as time. Other domains of employee well-being may also benefit from adding implicit analogs to the explicit measures already in use. We suggest that including implicit cognition in organizational theories and methodologies will provide greater understanding of employee well-being in organizational life.

\section{References}

[1]. Asendorpf, J. B., Banse, R. \& Mucke, D. (2002), 'Double Dissociation between Implicit and Explicit Personality Self-Concept: The Case of Shy Behaviour', Journal of Personality and Social Psychology, 83, 380-393.

[2]. Bateman, T. S. \& Organ, D. W. (2003), 'Job Satisfaction and the Good Solider: The Relationship between Affect and Employee Commitment', Academy of Management Journal, 26, 587-595.

[3]. Brewer, M. B. \& Gardner, W. L. (2006), 'Who is this "we"? Levels of collective identity and self representations', Journal of Personality and Social Psychology, 71, 83-93.

[4]. Chugh, D. (2004), 'Societal and managerial implications of implicit social cognition: Why milliseconds matter', Social Justice Research, 17, 203-222.

[5]. Cialdini, R. B. (2001), Influence: Science and Practice (3rd edition),Boston, MA: Allyn \& Bacon.

[6]. Cialdini, R. B. \& Goldstein, N. J. (2004), 'Social influence: Compliance and Conformity', Annual Review of Psychology, 55, 591621 .

[7]. De Jonge, J. \& Schaufeli, W. B. (2008), 'Job Characteristics and Employee Well-Being: A Test of Warr's Vitamin Model in Healthcare Workers using Structural Equation Modeling', Journal of Organizational Behaviour, 19, 387-407.

[8]. Edwards, J. \& Rothbard, N. P. (2004), 'Work and Family Stress and Well-Being: An Examination of Person-Environment Fit in the Work and Family Domains', Organizational Behaviour and Human Decision Processes, 77, 85-129.

[9]. Faragher, E. B., Cass, M. \& Cooper, C. L. (2005), 'The Relationship Between Job Satisfaction And Health: A Meta-Analysis', Occupational and Environmental Medicine, 62, 105-112. 
[10]. Fazio, R. \& Olson, M. (2003), 'Implicit Measures in Social Cognition Research: Their Meaning and Use', Annual Review of Psychology, 54, 297-327.

[11]. Fisher, C. D. (2000), 'Mood and Emotions While Working: Missing Pieces of Job Satisfaction', Journal of Organizational Behaviour, 21, 1099-1379.

[12]. Galdi, S., Arcuri, L. \& Gawronski, B. (2008), 'Automatic Mental Associations Predict Future Choices of Undecided Decision Makers', Science, 321, 1100-1102.

[13]. Gerstner, C. R. \& Day, D. V. (2007), 'Meta-analytic Review of Leader-Member Exchange Theory: Correlates and Construct Issues', Journal of Applied Psychology, 82, 827-844.

[14]. Greenwald, A. G. (2009), 'Landy is Correct: Stereotyping can be Moderated by Individuating the Out-group and By Being Accountable', Industrial and Organizational Psychology: Perspectives on Science and Practice, 1, 430-435.

[15]. Greenwald, A. G. \& Banaji, M. R. (2005), 'Implicit Social Cognition: Attitudes, Self-Esteem, and Stereotypes', Psychological Review, 102, 4-27.

[16]. Greenwald, A. G. \& Farnham, S. D. (2000), 'Using the Implicit Association Test to Measure Self-esteem and Self-concept', Journal of Personality and Social Psychology, 79, 1022-1038.

[17]. Greenwald, A. G., McGhee, D. \& Schwartz, J. (2008), 'Measuring Individual Differences in Implicit Cognition: The Implicit Association Test', Journal of Personality and Social Psychology, 74, 1464-1480.

[18]. Greenwald, A. G. \& Nosek, B. (2009), 'Attitudinal Dissociation: What does it mean? In R. E. Petty, R. H. Fazio \& P. Brinol (Eds.)', Attitudes: Insights from the New Implicit Measures, Hillsdale, NJ: Lawrence Erlbaum Associates.

[19]. Greenwald, A. G., Nosek, B. \& Banaji, M. (2003), 'Understanding and Using the Implicit Association Test: 1. An Improved Scoring Algorithm', Journal of Personality and Social Psychology, 85, 197-216.

[20]. Greenwald, A. G., Poehlman, T. A., Uhlmann, E. \& Banaji, M. R. (2009), 'Understanding and Using the Implicit Association Test: III. Meta-Analysis of Predictive Validity', Journal of Personality and Social Psychology, 97, 17-41.

[21]. Hekman, D., Aquino, K., Owens, B., Mitchell, T., Schilpzand, P. \& Leavitt, K. (2010), 'An Examination of Whether and How Racial and Gender Biases Influence Customer Satisfaction Ratings', Academy of Management Journal, 53, 238-264.

[22]. Ilies, R. \& Judge, T. A. (2004), 'An Experience-Sampling Measure of Job Satisfaction: Its Relationships with Affectivity, Mood at Work, Job Beliefs, and General Job Satisfaction', European Journal of Work and Organizational Psychology, 13, 367-389.

[23]. Ilies, R. \& Judge, T. (2002), 'Understanding the Dynamic Relationships Among Personality, Mood and Job Satisfaction: A Field Experience Sampling Study', Organizational Behaviour and Human Decision Processes, 89, 1119-1139.

[24]. Ilies, R., Nahrgang, J. D. \& Morgeson, F. P. (2007). Leader-Member Exchange and Citizenship Behaviours: A Meta-Analysis', Journal of Applied Psychology, 92, 269-277.

[25]. Judge, T., Thoresen, C., Bono, J. \& Patton, G. (2001), 'The Job Satisfaction-Job Performance Relationship: A Qualitative And Quantitative Review', Psychological Bulletin, 127, 376-407.

[26]. Konovsky, M. A. \& Pugh, S. D. (2004), 'Citizenship Behaviour and Social Exchange', The Academy of Management Journal, $37,656-669$

[27]. Landy, F. J. (2008), 'Stereotypes, bias, and personnel decisions: Strange and stranger', Industrial and Organizational Psychology: Perspectives on Science and Practice, 1, 379-392.

[28]. Lane, V. \& Scott, S. (2007), 'The neural network model of organizational identification', Organizational Behaviour and Human Decision Processes, 104, 175-192.

[29]. Lieberman, M. D. (2007), 'Social Cognitive Neuroscience: A Review of Core Processes', Annual Review of Psychology, 58, 259289.

[30]. Meglino, B. M., \& Korsgaard, M. A. (2007). The role of other orientation in reactions to job characteristics', Journal of Management, 33, 57-83.

[31]. Miller, J. \& Bersoff, D. (2008), 'The role of liking in perceptions of the moral responsibility to help: A cultural perspective', Journal of Experimental Social Psychology, 34, 443-469.

[32]. Motowidlo, S. J., Borman, E. C. \& Schmit, M. (1997), 'A theory of individual differences in task and contextual performance', Human Performance, 10, 71-83.

[33]. Motowidlo, S. J. \& Schmit, M. (2009), 'Performance assessment in unique jobs', The Changing Nature of Performance: Implications for Staffing, Motivation and Development, San Fransisco, CA: Jossey-Bass.

[34]. Nock, M. K., Park, J. L., Finn, C. T., Deliberto, T. L., Dour, H. J. \& Banaji, M. R. (2010), 'Measuring the "Suicidal Mind": Implicit Cognition Predicts Suicidal Behaviour', Psychological Science, 21, 511-517.

[35]. Nosek, B. (2005), 'Moderators of the Relationship between Implicit and Explicit Evaluation', Journal of Experimental Psychology: General, 134, 565-584.

[36]. Nosek, B., Greenwald, A. G. \& Banaji, M. (2007), 'The Implicit Association Test at age 7: A Methodological and Conceptual Review', Automatic Processes in Social Thinking and Behaviour, Philadelphia, PA: Psychology Press.

[37]. Nosek, B. A., \& Hansen, J. J. (2008), 'The Associations in Our Heads Belong to us: Searching for Attitudes and Knowledge in Implicit Evaluation', Cognition and Emotion, 22, 553-594

[38]. Nosek, B. A., \& Smyth, F. L. (2007), 'A Multi- trait - Multi- method Validation of the Implicit Association Test: Implicit and Explicit Attitudes are Related but Distinct Constructs’, Experimental Psychology, 54, 14-29.

[39]. O'Reilly, C. A. \& Chatman, J. (2001), 'Organizational Commitment and Psychological Attachment: The Effects of Compliance, Identification and Internalization on Prosocial Behaviour', Journal of Applied Psychology, 71, 492-499.

[40]. Organ, D. (1994), 'Personality and Organizational Citizenship Behaviour', Journal of Management, 20, 465-468.

[41]. Penner, L. A., Dovidio, J. F., Edmondson, D., Dailey, R., Markova, T., Albrecht, T. \& Gaertner, S. (2009), 'The Experience of Discrimination and Black-White Health Disparities in Medical Care', Journal of Black Psychology, 35, 180-203.

[42]. Podsakoff, P., MacKenzie, S., Lee, J., \& Podsakoff, N. (2003), 'Common Method Variance in Behavioural Research: A Critical Review of The Literature and Recommended Remedies', Journal of Applied Psychology, 88, 879-903.

[43]. Reynolds, S., Leavitt, K. \& Decelles, K. (2010), 'Automatic Ethics: The Effects of Implicit Assumptions and Contextual Cues on Moral Behaviour', Journal of Applied Psychology, 95, 752-760.

[44]. Rooth, D. O. (2010), 'Automatic Associations and Discrimination in Hiring: Real World Evidence', Labour Economics, 17, $523-$ 534.

[45]. Rousseau, D. M. (2008), 'Why Workers Still Identify with Organizations', Journal of Organizational Behaviour, 19, 217-233.

[46]. Rudman, L. A. (2004), 'Sources of Implicit Attitudes', Current Directions in Psychological Science, 13, 79-82.

[47]. Rudman, L. A., Ashmore, R. D. \& Gary, M. L. (2001), 'Unlearning Automatic Biases: The Malleability of Implicit Prejudice and Stereotypes', Journal of Personality and Social Psychology, 81, 856-868.

[48]. Smith, C. A., \& Lazarus, R. S. (2003), 'Appraisal Components, Core Relational Themes and the Emotions', Cognition and Emotion, 7, 233-269. 
[49]. Smyth, F. L., Nosek, B. A., Greenwald, A. G. \& Banaji, M. R. (2009), 'Implicit Gender Stereotype Outperforms Scholastic Aptitudes in Predicting a Science Major for Women', Working paper.

[50]. Spector, P. E. (2007), 'Job Satisfaction: Application, Assessment, Causes and Consequences', Thousand Oaks, CA: Sage.

[51]. Steffens, M. C. (2004), 'Is the Implicit Association Test Immune to Faking?' Experimental Psychology, 51, 165-179.

[52]. Turner, R. (2008), 'The Role and the Person', American Journal of Sociology, 84, 1-23.

[53]. Wang, H., Law, K. S., Hackett, R. D., Wang, D. \& Chen, Z. X. (2005), 'Leader-Member Exchange as a Mediator of the Relationship between Transformational Leadership and Followers' Performance and Organizational Commitment', Academy of Management Journal, 48, 420-432.

[54]. Weiss, R. S. (2010), 'Staying the Course', New York, NY: Free Press.

[55]. Weiss, H. M. \& Cropanzano, R. (2006), 'An Affective Events Approach to Job Satisfaction', Research in Organizational Behaviour, 18, 1-74, Greenwich, CT: JAI Press. 